\title{
Associativismo e sindicalismo em tempos de mal-estar
}

GINDIN, J.; FERREIRA, M. O. V.; ROSSO, S. dal. Associativismo e sindicalismo em educação: teoria, história e movimentos. Brasília: Ed. Paralelo 15, 2013.

\section{Lúcio Alves de Barros ${ }^{1}$}

O livro organizado por Julián Gindin, Márcia Ondina Vieira Ferreira e Sadi Dal Rosso é uma boa indicação de leitura para aqueles que estudam o "movimento dos trabalhadores da educação", "o sindicalismo docente" ou as "associações docentes". Em tempos nos quais a desvalorização é norma e o assalariamento é regra, sem falar da repressão e da violência contra os professores, o livro cai como luva nas mãos que se dedicam à temática. A leitura da obra nos leva para vários campos, como a dificuldade que os sindicatos - tanto aqui no Brasil como em outros países, como Portugal, México, Peru, Argentina e Estados Unidos - vêm enfrentando na organização de campanhas salariais, configuração da identidade laboral ou mobilização da base trabalhadora.

Na leitura da obra percebe-se que os problemas enfrentados pelos professores são complexos, mas nem por isso deixados de lado pelos sindicatos. É possível, por exemplo, colocar em questão a própria atividade docente, porque, além de interativa, ela é intangível e um objeto difícil de pesquisa. Talvez somente essas palavras sejam suficientes para a leitura atenta do texto de André Robert ("Os sindicatos de professores e a pesquisa em educação. Sobre alguns deslizes epistemológicos"), o qual se preocupa com a epistemologia e com as teorias que podem auxiliar

1 Doutor em Ciências Humanas: Sociologia e Política pela Universidade Federal de Minas Gerais. Professor na Faculdade de Educação da Universidade do Estado de Minas Gerais -UEMG. luciobarros460@gmail.com 
na análise do trabalho docente. $\mathrm{O}$ texto nos convida a compreender o objeto em pesquisa à luz de teorias de Bachelard, Bruno Latour, Merton ou Thomas Khun. Apesar de o texto ser denso não é difícil identificar o aviso do autor que nos aponta para a necessidade de uma análise que leve em consideração uma "epistemologia comum ao sindicalismo", ou seja, a que leve em consideração os saberes colocados pela ciência e os saberes construídos no cotidiano pelos militantes nos sindicatos.

O caso português é o primeiro artigo que descreve o associativismo docente. A análise é de Antonio Teodoro, Rosa Serradas Duarte e Maria Neves Gonçalves ("Associativismo, sindicalismo e identidade(s) docente(s). Algumas particularidades do percurso português"). Podese dizer que o artigo faz parte do já conhecido campo das identidades. Nesse sentido, um percurso histórico é feito pelos autores e o leitor tem uma boa noção de como é o movimento dos trabalhadores da educação em Portugal. Os autores se apegam ao campo relacional e biográfico dos atores estudados, mostrando que ambos os percursos levam os participantes do movimento sindical à identificação de sua identidade. De todo modo, criticam uma espécie de "hierarquia estatutária", produto de relações conturbadas entre professores que lecionam em lugares diferenciados como no primário (e infantil), ensinos secundários e preparatórios e ensino superior. A conclusão é esperada e se fecha na crise de identidade que se abre, apontando para as mudanças e os obstáculos que os docentes devem enfrentar. Resumindo, na questão levantada pelos autores: "o sindicalismo docente tem futuro?"

$\mathrm{O}$ artigo de Bruce Copere, "Los sindicatos docentes em Estados Unidos: tendencias recientes y escenarios futuros", aponta para as relações contratuais, a negociação coletiva de acordo com alguns estados federados e a institucionalização de práticas na qual é inegável a importância dos professores como força coletiva. $\mathrm{O}$ autor destaca a preocupação com a diminuição da base sindical, a divisão dos sindicatos em relação à categoria em várias centrais sindicais ao gosto do mercado e a relação com outras profissões. É um texto que nos aponta as dificuldades de um país que, não raro, se coloca como exemplo de democracia.

$\mathrm{O}$ artigo de Adrián Ascolani, “La Internacional del Magisterio 
Americano: creación y repercusiones (1928/1930)", retrata e analisa a experiência dos movimentos dos trabalhadores uruguaios, chilenos e argentinos. O autor destaca a história da organização sindical Internacional del Magisterio Americano (IMA), em que se encontravam docentes chilenos, uruguaios e argentinos. Analisa que na Argentina ela conseguiu maior desenvolvimento devido ao golpe militar ocorrido em setembro. No Chile, a questão não foi diferente, as associações dos professores se colocaram contra a ditadura e auxiliaram na Frente Funcional Sindicalista. No Uruguai, o movimento dos professores apoiou a democracia, o antiamericanismo e defendeu a educação como direito universal. Tudo em uma época em que a inteligência e a cultura dos intelectuais eram colocadas em xeque. Foi a partir da luta dos professores que se discutiram nesses países os ideais democráticos, a consciência do valor da profissão e a injustiça social.

$\mathrm{O}$ "Sindicalismo docente en América Latina. Um ensayo sociológico" é o trabalho de Julian Gindin. Pretensioso, o autor argumenta sobre o sindicalismo docente desenvolvido na Argentina, Venezuela, Brasil, Chile, México e Bolívia. Nesses dois últimos países, argumenta que a organização dos professores como militantes populares e atrelados ao Estado garantiram a mobilização docente e uma relativa vida política de organizações com recursos e poder. O preço pago foi o atrelamento ao Estado. A diferença em relação aos outros países recai sobre a organização de oposições sindicais distantes do Estado. Os casos do Brasil, da Argentina e do Chile são emblemáticos, pois, apesar de haver interferência estatal nos anos de 1930-1950, assistiu-se a um movimento sindical independente e coeso.

O artigo de Sigfredo Chiroque, "Sindicalismo docente en el Perú: refundación em el marco neoliberal?", estuda o sindicalismo peruano, o qual sofreu sérias influências do grupo guerrilheiro Sendero Luminoso. Relata que o Sindicato Unitario de los Trabajadores en la Educación del Perú (SUTEP) teve grande importância na mobilização dos trabalhadores docentes nos anos de 1970 e 1980 . Nesse período descreve com acuidade certa institucionalização do sindicato, que sofreu com as manobras neoliberais, a precariedade da atividade docente e a dificuldade nas 
negociações com as autoridades governamentais. Segundo o autor, o sindicato neste país passa por uma crise na qual a educação libertadora foi deixada de lado em um sistema político ainda conservador e em uma sociedade alicerçada na desigualdade nos campos cultural e econômico.

Os artigos subsequentes, de Aldo Munoz, “El sindicato magisterial y La reforma educativa em El gobierno de La derecha: cohabitación y subordinación" e Aurora Loyo, "Los Maestros do México: de trabajadores de La educación a profesionales docentes? Implicaciones para el SNTE", tratam da situação vivenciada nos últimos anos pelos professores do México, notadamente pelos que estavam filiados ao que eles chamam de maior sindicato de professores da América Latina, o Sindicato Nacional de Trabajadores de la Educación (SNTE). Nos últimos anos, o sindicato esteve atrelado ao Partido Revolucionário Institucional (PRI) e manteve o seu poder mesmo com a mudança do poderio para as mãos do Partido da Ação Nacional (PAN). Os autores levantam as conquistas que foram ameaçadas durante os anos 2000. O atrelamento do sindicato ao Estado tem levado o movimento dos trabalhadores para uma perigosa encruzilhada, não somente pela volta do PRI ao poder, mas também pelas dificuldades de mobilização e renovação de lideranças simpáticas ao governo. A ação sindical tem sido de "estabilidade governamental", em que os dirigentes, de acordo com Aldo Munõz, têm garantido uma "intelocución fluida" no intuito de levar a efeito projetos no campo da educação.

São sete os capítulos que se referem ao Brasil. O artigo de Amarildo Ferreira Jr., " A Confederação dos Professores do Brasil e a aposentadoria

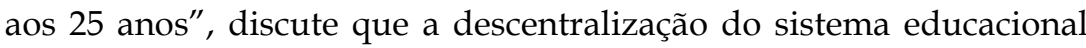
brasileiro impôs características particulares para as pesquisas referentes à educação. As três esferas governamentais (municipal, estadual e federal), apesar das diferenças, encontraram na luta por 25 anos de trabalho uma ótima ocasião para unificar interesses que, geralmente, não trilham o mesmo caminho de negociação. A luta foi adiante devida a ação da Confederação de Professores do Brasil (CPB) nas décadas de 1970 e 1980. A coragem e a determinação de lideranças, em pleno governo militar, foi alimentada pelos bons ventos em favor da democracia. A luta em questão 
simbolizou não somente uma guinada rumo ao Estado democrático de direito, mas também à construção de uma nova identidade profissional.

O artigo de Paula Perin Vicentini e Rosário S. Genta Lugli, “O magistério secundário e o associativismo em São Paulo ente os anos 19401960: a trajetória da Associação dos professores do Ensino Secundário e Normal Oficial do Estado de São Paulo", analisa as representações da profissão docente no magistério secundário. A análise se assenta na década de 1940, e os autores se fixam na configuração de categorias capazes de revelar e legitimar o exercício da docência no ensino secundário. Com base na melhora do estatuto profissional, eles se apegam ao estudo da Associação dos Professores do Ensino Secundário e Normal oficial do Estado de São Paulo (APENOESP) - entidade que passou, em 1971, a ser chamada de Associação de Professores do Ensino Oficial do Estado de São Paulo (Apeosp) - e, desde 1988, tornou-se sindicato. O artigo, na esteira de Bourdieu, identifica um campo de heterogeneidade da categoria proveniente das mudanças, porque passou o trabalho docente. Diferenciação oriunda do processo de heterogeneidade ao longo do tempo entre professores primários e a delimitação do campo da educação como espaço de decisões técnicas e não de decisões políticas. $\mathrm{O}$ conhecimento técnico, legitimado pelo Ministério da Educação, alcançou um estatuto privilegiado em detrimento da licenciatura. Essa ação resultou em conflitos e perdas para a categoria. Nos anos 1950, os autores alertaram para a organização e o aumento da participação dos professores nas assembleias permanentes. O decênio de 1960 apareceu como um momento de reivindicação e posterior cristalização da condição docente. A "representação" docente como um "profissional" do funcionalismo público não contemplava o reconhecimento demandado. Pelo contrário, ele reforçava a proletarização e sua consequente desvalorização salarial.

O artigo de Ricardo Pires de Paula, "A greve do magistério público no estado de São Paulo em 1963: ações e representações", retrata os primeiros anos de existência da Associação dos Professores do Ensino Secundário e Normal Oficial do Estado de São Paulo (Apesnoesp) até a greve de 1963. Os relatos dos atores da organização da greve é o ponto alto do texto não somente devido ao momento político vivido no Brasil, 
como o parlamentarismo que levou João Goulart ao poder, mas por todas as mudanças por que o país passava. A greve era colocada como tabu e as manifestações públicas contavam com servidores públicos e muitos professores. Nesse campo, a greve teria marcado a passagem da ideia de sacerdócio docente para o conceito de docente profissional. As reivindicações em torno de melhores condições salariais e de trabalho ganharam as ruas e muitos alunos ficaram sem aulas. Todavia, os professores não se reuniram somente em torno da educação: a luta apontou para as denominadas "reformas de base", e a pauta política ganhou importância em meio aos docentes.

$\mathrm{O}$ artigo de Renato Kendy Hidaka, "Sindicalismo docente e reforma neoliberal no Estado de São Paulo", analisa o caminho percorrido pelo sindicato dos professores na década de 1990, quando teve que lidar com as mudanças oriundas da frente neoliberal do estado. Para isso, o autor descreveu as diretrizes político-ideológicas do denominado "neoliberalismo", as ações dos professores contra as determinações governamentais, notadamente dos governos de Mário Covas e Geraldo Alckmin, ambos do Partido da Social Democracia Brasileira (PSDB) e a posição política contrária das associações sindicais em relação ao projeto governamental. Apesar dos retrocessos, os sindicatos se colocaram contra boa parte das determinações do governo de SP e legitimaram as negociações coletivas em prol de um "sindicalismo propositivo" e de um plano institucional alternativo ao do governo. As denúncias contra o enxugamento da máquina educacional, a luta contra a desvalorização do professor, as críticas em relação ao tratamento do governo com a rede de ensino e o descaso com as mobilizações de base levou os atores sindicais a conflitos com os agentes governamentais. Em determinados momentos, especialmente no final da década de 1990, os sindicalistas optaram pela denúncia e pela inflexibilidade relacional; em outros episódios optaram por alternar negociação e aceitação do projeto do governo. A oscilação no comportamento sindical levou o autor a concluir que as alterações levadas a efeito pelos neoliberais na educação em São Paulo - não no todo, mas em boa parte - foram implantadas.

$\mathrm{O}$ artigo "Associativismo e sindicalismo de professores no Piauí: 
continuidades e rupturas no processo de organização (1959/1970)" é uma contribuição de Romildo de Castro Araújo e Antonio de Pádua Carvalho Lopes. Os autores apresentam um estudo histórico sobre o associativismo no estado do Piauí, o qual permite ao leitor se ambientar de novas configurações do que é fazer movimento de trabalhadores em um cenário no qual ainda se discute o processo de profissionalização do magistério. $\mathrm{O}$ artigo tem por base as experiências dos professores do ensino secundário da rede pública. Apesar de toda luta, percebemse avanços e retrocessos. Como avanços, destacam-se a formação de associações docentes, a configuração de uma base operária, greves e mobilizações. Os retrocessos ficam por conta de um sindicalismo caduco em suas ações, pois boa parte da vida existencial das associações se deu em período ditatorial e a anulação do sindicalismo docente era alimentada pelo medo e pela incerteza. $\mathrm{O}$ desconhecimento dos interessados por parte do governo fortaleceu a roupagem pelega do sindicalismo daquele estado, o qual, neutralizado em sua capacidade de mobilização, não foi capaz de constituir identidade, limitando-se a lutas imediatas, como o salário, a melhoria das condições de trabalho e o estatuto profissional. O sindicalismo do Piauí conseguiu certa projeção somente depois que se integrou às mobilizações docentes do restante do Brasil já no decênio de 1970.

A professora Maria da Consolação Rocha e Wanderson Paiva Rocha, "A luta em defesa da educação pública e as repercussões na organização sindical: o caso da Rede Municipal de Belo Horizonte", fazem uma análise histórica da organização sindical da rede municipal da capital de Minas Gerais. O artigo tem por início a década de 1980 e se desenvolve trazendo um histórico da constituição da RME/BH. Também descreve a organização sindical do magistério público em Minas e a organização e a estrutura sindical cutistas ocorridas nas décadas de 1980 e 1990. Os autores finalizam o artigo apresentando a fundação do SindRed/BH e as alternativas de organização dos trabalhadores revendo atividades que remontam as décadas de 1970 a 2000.

Alessandro Rubens de Matos e Carlos Bauer no artigo, “ A trajetória do sindicalismo dos profissionais em educação no ensino municipal de São 
Paulo (1988 -2004)", descrevem a trajetória do Sindicato dos Profissionais em educação no Ensino Municipal de São Paulo (Sinpeem). Os autores traçam as origens do sindicato, suas lutas, conquistas e obstáculos ao longo da história da organização da instituição e da cidade. Percebe-se que a trajetória do sindicato segue as mudanças políticas na educação e o aumento substancial de sua base operária. Assim, observa-se a falácia da educação como prioridade tanto no governo Jânio Quadros como nos governos de Luiza Erundina, Paulo Maluf / Celso Pitta (2001-2004) e Marta Suplicy. O texto deixa evidentes as mudanças que passaram os professores em cada gestão, com ênfase principal às reivindicações que até hoje fazem parte da pauta de discussão sindical como salários, os direitos, as condições de trabalho, a qualidade no ensino e a necessidade de maiores investimentos. Os autores deixam clara a peculiaridade da luta em cada governo e, apesar das ideologias, as reivindicações sofreram mudanças, adaptações e retrocessos. Em alguns governos, as lideranças deixaram a desejar e seguiram as regras governamentais; em outros, como os de oposição, o sindicato se colocou contra a ideologia conservadora, mas se rendeu a governos de "esquerda", a ponto de aceitar diretrizes assentadas em sistemas de gratificações por mérito e classificação de escolas por pontos. Mais que isso, os professores se submeteram à política de bônus, tiveram boa parte de suas reivindicações não atendidas e assistiram ao retrocesso da classe e a precarização do seu trabalho.

O livro é denso em sua complexidade e rico em informações. Contudo, é bom levantar algumas questões que não raro nos povoam a cabeça. Dentre tantas, é bom perguntar se o problema que perpassa a categoria dos docentes é universal. A maioria dos autores se apega à natureza do trabalho e muitos se esquecem de que professores atuam em diferentes esferas revestidas de diferentes fontes de valor trabalho. No caminho da "diferença", os sindicatos não estariam sofrendo com a diminuição da base sindical docente?

É forçoso ressaltar a questão do velho problema da profissionalização. Qual é o lugar da profissão professor? Ou os docentes são somente empregados do governo e das entidades privadas que cumprem a 
missão de fazer funcionar uma máquina cuja demanda é infinita? Não há dúvida que existem muitas faces do sindicalismo que, desde os estudos clássicos no Brasil, defendiam uma "nova" postura sindical ao final dos anos 1970. O tema do "novo sindicalismo" deixou a desejar aqui e acolá no livro e a burocratização sindical aparentemente ganha vida em uma leitura atenta e pessimista.

Por último, é bom apontar para duas questões: a primeira é sobre a mudança de perspectiva de muitas bandeiras de luta no campo do sindicalismo, como o contrato coletivo de trabalho, a unicidade sindical, o imposto sindical, a reforma da CLT etc. Em segundo, cumpre lembrar a luta que se travou a partir dos anos de 1990, com o chamado neoliberalismo, com a mudança da ideia de "esquerda" (oposição) e "direita" (situação) frente à entrada de lideranças sindicais no poder e o esperado abandono do "piso fabril" (sala de aula). Sem falar do paralelismo com o poder da situação e o famigerado debate acerca do fim e do mal-estar no movimento sindical docente. 